\title{
Cultura política e processo eleitoral no Brasil
}

\section{Ramon Taniguchi Piretti Brandão}

1 Mestre em Ciências Sociais pela Universidade Federal de São Paulo e Graduado em Ciências Sociais, Brasil. E-mail: ramonbrandao41@hotmail.com

RESUMO: O presente artigo se consagra a problematizar a cultura política do Brasil. Veremos quais foram as implicações - político-sociais - de uma cultura colonizada e baseada na exploração, escravidão e autoritarismo político. Trataremos historicamente a questão, percorrendo um período que vai do final do século XIX até o final da década de 1990. Evidentemente, devido ao extenso período histórico, nossa proposta gira em torno mais de uma problematização macro cultural da dinâmica política e suas consequências nos processos eleitorais do que uma problematização específica que pretenda esgotar alguma questão.

Palavras-chave: Cultura política. Processo eleitoral. História do Brasil.

\section{Political culture and electoral process in Brazil}

ABSTRACT: This article is devoted to discuss the political culture of Brazil. We will see what were the implications - political and social - of a colonized culture based on exploration, slavery and political authoritarianism. We treat historically this question, traveling a period from de late nineteenth century until the 1990 decade. Of course, because of the extensive historical period, our proposal revolves around more than a macro-cultural problematic of political dynamic and its consequences in the electoral process than a specific questioning wishing to exhaust some question.

Keywords: Political culture. Electoral process. History of Brazil.

\section{ELEIÇÕES NO BRASIL: BREVE RETOMADA HISTÓRICA}

O Brasil, sob o domínio colonial português e diferentemente das treze colônias da América do Norte britânica, não passou por um processo de aprendizagem sólida de autogoverno representativo. Ao longo de três séculos, o Brasil foi administrado por governadores-gerais, vice-reis, capitãesgerais, juízes, magistrados e outros burocra- tas portugueses menos importantes (BETHELL, 1987).

A primeira eleição realizada no país - que escolheria os delegados que representariam o Brasil nas cortes convocadas em Lisboa, logo após a Revolução Portuguesa de 1820 - só aconteceu entre maio e setembro de 1821. Na ocasião, por conta da transferência da corte portuguesa de Lisboa para o Rio de Janeiro (transferência ocorrida em 1808 durante as guerras napoleônicas), o Brasil já 
não era uma colônia portuguesa, mas um parceiro em igualdade de condições num regime de monarquia dual. Um ano depois das primeiras eleições, especificamente em junho de 1822, ocorreu uma segunda eleição - indireta e com sufrágio limitado - que nomearia uma Assembleia Constituinte (sediada no Rio de Janeiro). Foi ali, devemos pontuar, que o Brasil encaminhou-se, de fato, para a separação total de Portugal.

A independência do Brasil, em 1822, pode ser considerada como parte do que se chamou de revolução democrática do mundo atlântico, ocorrida no final do século XVIII e início do XIX. Este movimento pregava algumas ideias democráticas e liberais, firmando uma resistência contra o colonialismo e o absolutismo dos portugueses. No entanto, nunca houve no Brasil - sociedade construída com base na escravidão - qualquer intenção de criar uma organização política que se baseasse, ainda que teoricamente, na democracia representativa liberal, que se baseasse na soberania do povo ${ }^{1}$. A exemplo dos Estados hispano-americanos recém independentes, o Brasil não era, sequer, uma República. Antes, e de maneira singular, proclamou-se um Império - com Dom Pedro I, filho do rei João VI de Portugal e herdeiro do trono português, tornando-se o primeiro imperador do Brasil independen$\mathrm{te}^{\underline{2}}$. Desde então - e até o final dos anos de 1980 - o Brasil teve uma longa história de eleições regulares - mas não democráticas

\footnotetext{
${ }^{1}$ Cabe dizer que, na época, a população do país, num vasto território de aproximadamente 6,5 milhões de quilômetros quadrados, ficava entre quatro e cinco miIhões de habitantes, dentre os quais menos de um terço brancos e mais de um terço escravos.

2 Sobre a independência brasileira, ver BETHELL, Leslie. "A independência do Brasil" (2001) e VIOTTI DA COSTA, Emilia. "The political emancipation of Brazil" (1975) e "Independence: the building of a nation" (1985).
}

-, com exceção do período denominado Estado-Novo, que perdurou de 1937 a 1945. No entanto, ao longo do mesmo período, as eleições nem sempre foram para cargos de poder político (executivo ou legislativo) e não foram disputadas livres e competitivamente. São vastos, aliás, os relatos históricos que comprovam que as eleições do Brasil ao longo do período estiveram muito mais relacionadas a demonstrações públicas de lealdade pessoal (com a oferta e a aceitação do clientelismo), com a redução de tensões e conflitos sociais através da força e, sobretudo, com o controle do Estado patrimonial por meio do uso do poder público em prol de interesses privados, do que com o exercício do poder pelo/para o povo. Em outras palavras, antes de 1989, o Brasil era um país com eleições regulares mas não democráticas.

No contexto do Império, apesar do Brasil possuir uma Câmara de Deputados eleita, os governos, na prática, pouco prestavam contas a ela. O poder estava concentrado quase totalmente nas mãos do imperador (cargo hereditário), dos ministros por ele escolhidos, dos conselheiros de Estado (cargos vitalícios) nomeados pelo imperador, dos presidentes de província (também nomeados pelo imperador) e de um Senado (com cargos vitalícios e nomeados pelo imperador). Somente em 1989, quando o Brasil finalmente se tornou uma República, é que o Executivo (presidente, governador, e prefeito), assim como o Senado e a Câmara dos Deputados, as assembleias estaduais e as câmaras dos vereadores, passaram a ser eleitos pelo voto.

Um ponto curioso é que, ao longo da ditadura militar no Brasil, foram eleitos presidentes com mandato fixo, o que é bastante incomum em regimes dessa natureza. Fo- 
ram todos eleitos indiretamente por um Colégio Eleitoral do qual - ao menos até o ano de 1984 - o regime podia contar com a maioria. Na prática, isso significa que todos os cinco presidentes militares que comandaram o Brasil no regime militar foram impostos pelo alto comando do exército. Os governadores de estado - até 1982 - e os prefeitos de capitais e cidades estratégicas eram, também, nomeados pelos militares. O Congresso e as assembleias, que continuaram a funcionar sob o regime militar (exceto por pontuais fechamentos), embora com poderes notadamente reduzidos, foram as únicas a serem eleitas diretamente $\mathrm{e}$ com regularidade a cada quatro anos.

Retornando ao Império, o voto nas eleições era aberto. Eram muito comuns as fraudes, as intimidações, a violência e o clientelismo tanto pelos proprietários de terra locais quanto pelos agentes da Coroa. Somente em 1932, é que o voto tornou-se secreto, nascendo ali um sistema de supervisão eleitoral (a justiça eleitoral). No entanto, na prática, essa nova legislação só foi totalmente implementada no Brasil após o término da Segunda Guerra Mundial, mas sua implementação não durou vinte anos. Com a ascensão do regime militar no Brasil, as regras eleitorais passaram a ser frequente e escancaradamente manipuladas - e da maneira mais arbitrária possível - garantindo a maioria de parlamentares para o partido dominante, favorável aos interesses militares.

Nas eleições parlamentares do Império, eram três as opções: os liberais, os conservadores e os republicanos e, ao longo da Primeira República, o resultado das eleições presidenciais era previamente determinado pelos governadores de estado. Para que se tenha uma ideia, nenhum candidato oficial, apoiado pelos governadores e pela máquina política republicana de pelo menos um dos dois Estados com maior eleitorado (no caso, São Paulo e Minas Gerais), jamais perdeu uma eleição presidencial.

Com exceção do Partido Comunista Brasileiro (PCB), fundado em 1922 e declarado imediatamente ilegal e do partido fascista Ação Integralista Brasileira (AIB), fundado em 1932 e também considerado ilegal juntamente a todos os outros partidos políticos durante o Estado Novo -, não houveram partidos nem movimentos políticos nacionais até 1945.

Após a Segunda Guerra, mais de doze partidos políticos nacionais competiram por cargos pela primeira vez. No entanto, em maio de 1947 (após o início da Guerra Fria), o PCB - mais expressivo dos partidos de esquerda - fora novamente declarado ilegal pelo Congresso, após apenas dezoito meses de legalidade. O partido, que não era totalmente comprometido com as estratégias e a via eleitoral para se chegar ao poder, foi efetivamente excluído da política democrática e permaneceu assim ao longo dos quarenta anos seguintes. Cabe dizer que, durante a maior parte do regime militar - sobretudo entre as reformas partidárias de 1966 e 1979 - apenas dois partidos tiveram a permissão de disputar eleições. São eles o partido governista ARENA (Aliança Renovadora Nacional), que depois se transformou em PDS (Partido Democrático Social) e o partido oposicionista MDB (Movimento Democrático Brasileiro), que depois se transformaria no PMDB (Partido do Movimento Democrático Brasileiro).

$\mathrm{O}$ auge do Império foi marcado pelo número elevado de votantes. Devemos nos lembrar que votantes eram os homens (muIheres não tinham a prerrogativa do voto), 
com idade a partir de 25 anos (ou 21 anos, quando casados), católicos e nascidos livres. O historiador Richard Graham (1990) calculou que, em 1870, cerca de um milhão de brasileiros - numa população total (incluindo mulheres e crianças) que não ultrapassava os dez milhões -, ou seja, algo que correspondia a mais ou menos metade da população masculina adulta e livre, podiam votar. A nível de exemplo, esta é uma fração muito maior da população do que os votantes na Inglaterra do mesmo período. No entanto, ao contrário da própria Inglaterra, as eleições eram indiretas. Os votantes brasileiros não elegiam seus representantes políticos; antes, elegiam eleitores (cerca de 20 mil) que tinham o direito de votar em deputados. Ademais, em períodos de eleição, o comparecimento desses eleitores era bastante reduzido.

Além disso, sobretudo após 1881, o nível de participação política no Império foi reduzido severamente. Já no final do século XIX, quando a economia cafeeira expandiu-se e a escravidão perdeu espaço para a mão-deobra livre, houve uma classe política dominante, mesmo entre os reformistas liberais, que temiam que ex-escravos adquirissem um nível de renda suficiente para que o seu direito ao voto fosse garantido. Com a Lei Saraiva de 1881, as eleições para a Câmara dos Deputados tornaram-se diretas e a idade mínima foi reduzida, definitivamente, de 25 para 21 anos; além do mais, a qualificação por propriedade/renda para votar foi abolida. Os não-católicos, os cidadãos naturalizados (com exceção dos estrangeiros imigrantes residentes no país) e os exescravos podiam se tornar votantes. Isso, aos olhos do liberalismo democrático, parecia ser um grande avanço. No entanto, no mesmo ano foi criada uma nova exigência para o registro de votantes: a alfabetização (na época, o país tinha entre 80 e $85 \%$ da população analfabeta). Assim, a vasta maioria dos brasileiros, mesmo a maioria dos homens livres que anteriormente votavam - embora fossem votos indiretos - foram deliberadamente excluídos da participação política. Dessa forma, o liberalismo pode ter sido a ideologia dominante no Brasil do século XIX, mas, ao mesmo tempo, era uma versão notadamente conservadora, convergente à realidade de uma cultura política autoritária, à realidade do subdesenvolvimento econômico e, acima de tudo, de uma sociedade marcada por sua estratificação profunda (sobretudo, segundo limites raciais).

Assim como o Império, a República também excluía da política a grande maioria dos brasileiros adultos ao negar o voto aos analfabetos (estima-se que, mesmo em 1920, mais de $75 \%$ da população ainda era analfabeta). Tais estatísticas e suas consequências eleitorais favoráveis aos interesses pessoais da elite política retratam o descaso da Primeira República com a educação pública. Para que se tenha uma ideia, a Assembleia Constituinte de 1891 esforçou-se mais em estender o sufrágio às mulheres (que tinham índices de analfabetismo tão altos quanto os homens) do que aos analfabetos (GRAHAM, 1990). Na cidade do Rio de Janeiro - capital da República na época -, com uma população média de meio milhão de habitantes, no início do século, estimase que apenas cem mil pessoas tiveram o direito de votar. Dos cem mil, somente $25 \%$ se registraram para votar nas eleições nacionais entre 1890 e 1910 . Dos 25\% registrados, apenas uma média de $10 \%$ efetivamente votaram. Isso representa de 5 a $10 \%$ da população (CARVALHO, 1987), um nú- 
mero assustadoramente baixo. Mesmo em eleições que envolveram maior mobilização política por parte da população - exemplo das eleições de 1910 e 1919, nas quais Rui Barbosa (um jurista liberal) se apresentou como candidato da oposição civilista (e perdeu) -, somente $5 \%$ da população adulta efetivou seu voto. Foi somente após 1930, que as eleições - no caso, as eleições presidenciais - do Brasil tiveram participação superior a $10 \%$ da população votante (LAMOUNIER; MUSZYNSKI, 1993). Uma Lei em 1932 reduziria para dezoito anos a idade mínima para votar e, importante, deu o direito de voto às mulheres, desde que fossem alfabetizadas (HAHNER, 1991). Os índices de votantes, no entanto, permaneceram muito baixos. Somente $15 \%$ das mulheres em condições legais de votar o fizeram.

Já em 1945, uma nova lei eleitoral incluía o registro automático de empregados homens e mulheres - de empresas públicas e privadas (muitos dos quais analfabetos); medida planejada para ampliar o voto a setores da classe trabalhadora urbana, ao mesmo tempo em que a população rural permanecia excluída de todo o processo. As eleições de 1945 foram as primeiras a serem disputadas democraticamente (no caso, até mesmo o Partido Comunista Brasileiro teve permissão para concorrer) e foram relativamente populares. No total, sete e meio milhões de brasileiros se registraram para votar - número de quatro a cinco vezes maior do que a quinze anos precedentes. No entanto, efetivamente pouco mais de seis milhões votaram (LAMOUNIER; MUSZYNSKI, 1993). Contudo, isso ainda significava que mais da metade da população adulta do Brasil ainda permanecia sem direito de voto, devido ao analfabetismo.
Mesmo assim, como resultado do rápido crescimento populacional (de 40 milhões em 1940 para 70 milhões em 1960, e 120 milhões em 1980), da rápida urbanização (cerca de 35\% da população, em 1940, foi classificada como urbana; 45\% em 1960 e 70\% em 1980) e, nas décadas de 1960 e 1970 , pela primeira vez, pelo progresso real na direção da alfabetização básica universal, o eleitorado cresceu exponencialmente. Em 1980, chegou a 18 milhões e, apesar do colapso da limitada forma de democracia do Brasil do pós Segunda Guerra, cresceu novamente em 1982, superando a marca de 60 milhões.

Ademais, foi somente em 1985, com o reestabelecimento do governo civil e numa das várias emendas constitucionais aprovadas nos primeiros meses do governo de José Sarney, que os analfabetos (em números que superavam 15 milhões de pessoas, ou seja, de 20 a $25 \%$ da população adulta) finalmente tiveram direito ao voto ${ }^{3}$.

As eleições municipais ocorridas em 1985, e as eleições para o Congresso e os governos de Estados ocorridos em 1986, foram as primeiras, em toda a história do Brasil, baseadas no sufrágio universal (BERQUÓ; ALENCASTRO, 1992). As consequências foram imediatas: o Congresso, entre os anos de 1987 e 1990, teve 26 muIheres como eleitas - número maior do que todo o período de 1932 a 1986 - e 19 negros, dentre as quais a primeira deputada negra (Benedita da Silva, do Partido dos Trabalhadores (PT) no Rio de Janeiro).

Em 1989, o Brasil viveria sua primeira eleição presidencial baseada no sufrágio universal. Foi realizada no centenário da Repú-

\footnotetext{
${ }^{3}$ Foi também aí que o direito ao voto foi estendido opcionalmente - para jovens a partir de dezesseis anos.
} 
blica (15 de novembro de 1989) com um eleitorado que superava os 82 milhões de votantes. Tendo em vista que, desde 1945, o voto no país era obrigatório (a Constituição de 1988 limitava a obrigação para pessoas entre dezoito e setenta anos), o comparecimento nas urnas foi bastante alto (cerca de 88\%). Na ocasião, candidatos de 22 partidos concorreram no primeiro turno. No segundo, apenas dois: Fernando Collor de Mello, do Partido da Reconstrução Nacional (PRN) e Luís Inácio Lula da Silva, do Partido dos Trabalhadores (PT). Por uma pequena margem (apenas seis pontos percentuais), os brasileiros elegeram Collor (LAMOUNIER; MUSZYNSKI, 1993).

O que se seguiu após a posse de Collor foram trágicas tentativas de reerguer a economia, que sofria com inflações exorbitantes, até que, em 1992, o país sofreria mais um trauma: o impeachment presidencial. Collor, o primeiro Presidente eleito democraticamente e não tendo concluído nem a metade do mandato previsto, esteve envolvido diretamente em vários escândalos de corrupção. Ademais, apesar de traumático no momento, o impeachment pôde ser visto, tempos depois, como demonstração mais de maturidade política do que de fragilidade institucional ${ }^{4}$.

Poucos anos depois, os brasileiros foram às urnas mais uma vez para eleger Fernando Henrique Cardoso ${ }^{\underline{5}}$ (cerca de 78 milhões

\footnotetext{
${ }^{4} \mathrm{O}$ ex-presidente Fernando Collor de Mello teve seu impedimento aprovado primeiro na Câmara dos Deputados, em 29 de setembro de 1992 (441 votos favoráveis ao impedimento contra 38 contrários) e depois, pelo Senado, em 30 de dezembro do mesmo ano (76 votos favoráveis contra 3) - um dia após a sua renúncia.

${ }^{5}$ Reconhecido por ideias democráticas e sociais, embora em seus dois mandatos, como veremos mais adiante,
}

de brasileiros votaram em 1994, o que representa $82 \%$ do eleitorado e, em 1998, cerca de 83 milhões de brasileiros, representando uma média de $78 \%$ do eleitorado ativo). Em 1998, Fernando Henrique Cardoso se tornou apenas o segundo presidente civil eleito a completar todo o mandato desde 1930 - o primeiro foi Juscelino Kubitschek na década de 1950. Por fim, Fernando Henrique Cardoso entraria para a história do Brasil como o primeiro presidente a ser reeleito (possibilidade viabilizada através de emenda constitucional criada em seu primeiro mandato).

O ambiente político-institucional da década de 1990 era, após longos anos, favorável para a consolidação da democracia não somente no Brasil, mas em toda a América Latina. Os Estados Unidos, por exemplo, tornou o apoio à democracias emergentes uma característica central em sua política externa, ao contrário do até então praticado intervencionismo político (lembremos que o apoio dos Estados Unidos foi pontual na viabilização do golpe militar de 1964). Além do mais - sobretudo com o fim da Guerra Fria -, não havia mais a desculpa do anticomunismo para justificar a derrubada de governos.

Deste modo, tanto a esquerda política do país quanto a direita - composta, sobretudo, pela classe política tradicional (rural e urbana), por grupos de interesse econômico mais poderosos e pelo alto escalão dos militares - estavam comprometidos com uma política democrática pacífica. Essa conclusão é facilmente compreendida quando tomamos de exemplo o impeachment de Collor. A crise política em torno de todo o

tenha sido eleito compondo uma coalizão de centrodireita.

https://periodicos.unifap.br/index.php/estacao Macapá, v. 6, n. 2, p. 17-32, maio/ago. 2016 
processo, em 1992, foi a primeira da história da República onde os militares - cujas prerrogativas de intervir no processo político em casos de instabilidade estão explicitamente reconhecidas na Constituição de 1988 - não foram participantes ativos. É evidente que podemos argumentar que as classes proprietárias brasileiras (incluindo setores extensos da classe média) eram - e ainda são - fair-weather democrats ou, "democratas de ocasião". Quando é alto o custo - político e social - para derrubar uma democracia (recorrendo ao autoritarismo) e baixo o custo de tolerar a democracia, esta última tende a sobreviver. Por outro lado, quando seus interesses são ameaçados por forças favoráveis à distribuição de riqueza e de poder, como acreditava-se acontecer em 1964, há sempre a possibilidade de que elas, a qualquer custo, procurem as forças militares.

\section{A DEMOCRACIA ELEITORAL NA DÉCADA DE 1990}

É possível haver eleições sem democracia, como a própria experiência brasileira nos mostra, mas não há democracia - ao menos a democracia representativa liberal - sem eleições. Evidentemente, o exercício de uma democracia não se resume ao mero acontecimento eleitoral. O exercício do poder entre as eleições também é muito significativo e importante na caracterização da democracia. A partir da década de 1990, as instituições políticas do país passaram a funcionar relativamente bem, não permanecendo nenhum enclave autoritário, ou seja, não permanecendo nenhuma parte do aparelho de Estado da antiga ditadura militar que não prestava contas aos governos civis e democraticamente eleitos. No entan- to, ainda assim, a recente democracia brasileira não deixa de ter suas imperfeições.

Cientistas políticos e outros estudiosos de sistemas políticos já afirmaram que, no Brasil, é o próprio sistema presidencial o obstáculo ao apropriado funcionamento da democracia representativa. O presidencialismo significaria o reforço do personalismo e de um certo autoritarismo profundamente enraizados na cultura política do país.

No entanto, por pior que seja o seu desempenho, o seu apoio no Congresso ou a sua popularidade, um presidente só pode ser destituído de seu cargo em casos extremos. No próprio Brasil também temos exemplos que ilustram a questão: Getúlio Vargas, em 1954, pelo suicídio; Jânio Quadros, em 1961, pela renúncia; João Goulart, em 1964, pelo golpe militar; Fernando Collor, em 1992, pelo impedimento. Outro ponto muito interessante e que merece menção é o de que o Brasil, em duas oportunidades após a ditadura militar, teve condições de mudar seu sistema de governo: em março de 1988, depois de árduo debate, a Assembleia Constituinte aprovou, por 344 votos contra 212, o sistema presidencial de governo, em vez do sistema parlamentar. Cinco anos depois, em abril de 1993, em plebiscito, $55 \%$ do eleitorado brasileiro votou em favor do presidencialismo, contra $25 \%$ em favor do sistema parlamentar e $20 \%$ de nulos e brancos. Neste mesmo plebiscito houve, também, a possibilidade de se votar pela restauração da Monarquia: $12 \%$ votaram a favor e $66 \%$ apoiaram a $\mathrm{Re}-$ pública (BETHEL, 2002).

O sistema eleitoral brasileiro, que se baseia na representação proporcional, mas com grandes distritos eleitorais e com listas abertas de candidatos, justamente com seu sistema partidário, tem sido passível de 
muitas críticas. Ambos, mas especialmente o sistema partidário, têm prioridade em todos os programas de reforma política. 0 Brasil, por isso, já foi descrito como o caso mais grave de subdesenvolvimento partidário entre todos os países democráticos do mundo (MAINWARING, 1992). Em sua grande maioria, os partidos não possuem raízes históricas profundas e sequer alguma coerência ideológica/programática. A nível de exemplo, no contexto da década de 1990 e com exceção do PT e do extinto PFL (atual DEM), quase um terço dos deputados eleitos em 1994 trocaram de partido durante a legislatura que perdurou de 1995 a 1998. Isso demonstra um altíssimo índice de indisciplina e um baixíssimo nível de coesão.

Finalmente há a questão do, segundo defendem alguns, excesso de partidos. Em nove eleições ocorridas entre os anos de 1982 e 1996, setenta e seis partidos apresentaram candidatos $^{\underline{6}}$. O PSDB, do então presidente Fernando Henrique Cardoso, elegeu apenas $12 \%$ das cadeiras do Congresso nas eleições de $1994^{\underline{7}}$. Tal contexto culminou no que foi chamado de "presidencialismo de minoria permanente" $\stackrel{8}{e}$, a partir de FHC, viu-se um esforço desmedido na busca por alianças partidárias, criando-se, assim, governos de coalizão que se pautam, sobretudo, na barganha política.

\footnotetext{
${ }^{6}$ Atualmente são trinta e cinco partidos registrados no Tribunal Superior Eleitoral (TSE), dentre os quais vinte e cinco são representados na Câmara. O partido político com o maior número de parlamentares é o Partido do Movimento Democrático Brasileiro (PMDB), com sessenta e oito deputados em exercício.

${ }^{7}$ Atualmente, está entre os cinco partidos políticos com maior número de cadeiras. São cinquenta deputados em exercício.

${ }^{8}$ Assim foi chamada pois nenhum presidente eleito pelo povo, desde 1950, teve a maioria dos parlamentares de seu próprio partido no Congresso.
}

Uma das características mais antidemocráticas da atual democracia brasileira - e, talvez, a mais difícil de se modificar - se respalda num sistema federativo que privilegia, sobretudo, os estados menos habitados do país - elegendo representantes em excesso no Congresso. O problema não está no fato de, como nos EUA, todos os 27 Estados do Brasil, independente de população, ter o mesmo número de cadeiras no Senado (três), mas que a representação na Câmara não seja proporcional à população nem ao eleitorado. Até o final da década de 1990 havia, na Câmara dos Deputados, um piso mínimo de oito cadeiras e um teto máximo de setenta cadeiras para cada estado. Neste contexto, São Paulo, com um eleitorado de mais de 20 milhões de pessoas, tinha as setenta cadeiras enquanto Roraima, com um eleitorado de 120 mil pessoas, tinha oito. Os sete menores Estados do Brasil em população (não em tamanho), que juntos respondem por apenas $4 \%$ da população de país, elegem $25 \%$ do Senado e mais de $10 \%$ da Câmara (STEPAN, 2002). Esse sistema claramente favorece os partidos mais fortes em Estados menos populosos, o que é bastante ruim para uma democracia. Para que tenhamos noção do que isso realmente significa, o PFL, com apenas dois ou três pontos percentuais a mais que o voto popular nacional obtido pelo PT em 1994 e 1998, elegeu três vezes mais senadores e praticamente o dobro de deputados federais.

Outro ponto reconhecidamente problemático é o da fragilidade do cumprimento da lei, mesmo depois de uma década de democracia. Até 1998, nenhum governo na história brasileira deu maior apoio aos direitos civis e humanos do que o do presidente Fernando Henrique Cardoso. No entanto, 
para a maioria da população (sobretudo das parcelas mais pobres), as liberdades civis mais básicas continuaram mal protegidas e garantidas pelos tribunais, sendo relativamente frequente as violações dos direitos humanos - cometidas, dentre outros, pela polícia militar (PINHEIRO, 2002). O Brasil ficaria reconhecido mundialmente por ser uma democracia de votantes, mas não de cidadãos.

Pesquisas de opinião pública conduzidas durante a década de 1990 indicaram a falta de confiança da população não somente nos políticos de modo geral, nos partidos e nas instituições políticas, mas na própria democracia. É relevante a informação de que grandes quantidades de eleitores, a cada ano, deixam de votar nas eleições, ainda que o voto seja tecnicamente obrigatório. Há, também, uma quantidade significativa de eleitores que votam em branco ou nulo - práticas comuns (e compreensíveis) durante um regime de domínio militar, mas perturbadoras numa democracia. De 1989 para 1994 a abstenção de votos cresceu de $11,9 \%$ para $17,7 \%$. Em 1998, o número bate os 21,5\%. Nas eleições presidenciais de 1989 , os que votaram em branco ou nulo foram 6,4\% dos eleitores; 18,8\% em 1994 e $18,7 \%$ em 1998. Em números significa que, em 1998, 38,4 milhões de brasileiros abstiveram-se de votar, anularam seu voto ou votaram em branco - para que se tenha uma ideia, esse número é maior do que a quantidade de eleitores que elegeram Fernando Henrique Cardoso (35,9 milhões de eleitores) no mesmo ano. O número de votos nulos e brancos nas eleições para o Congresso e os governos estaduais ficou em torno de 30\% (com exceção do Maranhão, Bahia e Pará, que alcançaram os $50 \%$ ). Isso deixa evidente que, a nível de democracias mundiais, esses índices são extraordinariamente altos.

A década de 1990 marcou um Brasil que, entre as dez principais economias do mundo, era - ao mesmo tempo - o sexagésimo na classificação internacional de desenvolvimento humano e fortíssimo candidato ao título de país com a maior desigualdade social do planeta. A extrema pobreza, a desigualdade social e a exclusão social (que tem claríssimas relações com um preconceito étnico - desconstruindo a falsa alegação de que o Brasil é uma democracia racial) têm suas raízes no colonialismo português, na escravidão, no subdesenvolvimento e "dependência" econômicos, na imigração em massa para o país no final do século XIX e início do $X X$, na rápida urbanização depois de 1940 e, sobretudo, em antigos fracassos no combate ao problema social exacerbado. Em outras palavras, o Brasil da década de 1990, como afirmou Erick Hobsbawm, é um "monumento à negligência social" ( BAWM, 1995, p. 397).

\section{AS ELITES E AS CLASSES POPULARES NA HISTÓRIA POLIITICA DO BRASIL}

Ao longo da história moderna do Brasil, todas as mudanças de regime político demonstraram a capacidade extraordinariamente alta das elites de defenderem seus próprios interesses. Instrumentos de controle, de cooptação e de repressão foram algumas das estratégias usadas contra as forças favoráveis à transformação social. Nas raras ocasiões em que as forças populares se mobilizaram para combater qualquer forma de status quo, sobretudo após 1930, as elites sempre estiveram prontas a tomar medidas para contê-las. Os exemplos de governos antipopulares e autoritários no 
Brasil - sobretudo o de 1937 à 1945 e o de 1964 à 1985 - são exemplos claros.

A independência do Brasil, em 1822, foi mais o resultado da evolução política e militar na Europa e sua consequente repercussão no Novo Mundo do que qualquer tipo de "crise" do sistema colonial escravista. Lembremos que, ainda em 1820, não havia no Brasil um consenso quanto à separação total de Portugal. O principal objetivo dos líderes ${ }^{9}$ e defensores da independência era o de conquistar autonomia política e econômica para o país sem que, para isso, sacrificassem a estabilidade social, tão necessária para a manutenção da unidade territorial e das estruturas socioeconômicas existentes e construídas, sobretudo, através da mão de obra escrava. Tanto que, uma vez decidida, a independência do Brasil foi garantida sem nenhum conflito, sem nenhuma mobilização social e muito rapidamente - ao contrário, por exemplo, das experiências vividas pela América espanhola. Tal característica do processo evidencia o fato de que as forças populares, na época, eram muito fracas - e divididas por classe, raça e condição legal. Assim, a transição da condição de Colônia portuguesa para Império independente foi caracterizada, sobretudo, pela manutenção e continuidade política, social e econômica. Isso significa, em outras palavras, que o aparelho de Estado português nunca deixou de operar no Brasil independente. $\mathrm{E}$ assim como o padrão existente de propriedade de terra, a instituição da escravatura também sobreviveu em todas as regiões do país que, embora muito concentradas na agricultura, se reproduzi-

\footnotetext{
9 As lideranças eram compostas, principalmente, por grandes latifundiários, mercadores e burocratas.
}

am em todos os setores da economia e da sociedade rural e urbana (VIOTTI, 1975).

No caso da escravidão, o movimento abolicionista da década de 1880, apesar de representar o nível de mobilização popular mais elevado dentre os quais até então já se havia visto, exerceu um papel relativamente pequeno na abolição final da escravatura $^{10}$. A abolição foi, antes, o resultado dos efeitos cumulativos da mudança econômica e demográfica de longo prazo, das fugas em massa de escravos e de libertações voluntárias por parte dos senhores. Foi, finalmente, o resultado do suprimento de uma fonte alternativa de mão-de-obra na forma de imigrantes italianos e de decisões políticas tomadas pelo governo imperial (BETHELL, 1991). O Brasil foi não só o último país independente das Américas a abolir a escravidão, como também o último a proclamar a República. A ideologia do republicanismo brasileiro - em especial a do republicanismo radical -, tomava como principal referência a Revolução Francesa. No entanto, não houve nenhuma revolução no Brasil antes de ser proclamada a independência. Como observou Louis Couty, francês que residia na cidade do Rio de Janeiro no início da década de 1880, "o Brasil não tem povo" (CARVALHO, 1987, p.10). No Brasil não havia uma unidade popular que pudesse ser organizada e mobilizada para fins políticos. A República brasileira nasceu de um golpe militar que reproduzia certo conchavo entre um pequeno número de oficiais do exército e de representantes da crescente oligarquia de proprietários de terras produtoras de café do Estado de São Paulo.

\footnotetext{
${ }^{10}$ Lembremos que, em 1870 o Brasil possuía mais de 1,5 milhões de escravos. Em 1880, esse número ainda ultrapassava um milhão.
} 
A chamada Revolução de 1930, que culminou no fim da Primeira República e no fim da hegemonia da oligarquia cafeeira de São Paulo, não pode ser considerada uma revolução. Getúlio Vargas, então governador do Rio Grande do Sul e recém derrotado nas eleições do mesmo ano, chegou ao poder através de uma rebelião armada liderada por membros dissidentes da elite política, assim como oficiais militares descontentes com a nomeação de Washington Luís. Tal rebelião - que, certamente, poderíamos chamar de golpe - contou com uma intervenção do exército federal para destituir o então presidente. Assim, a tomada do poder por Vargas representou, ao contrário do que se acreditava, mais uma mudança do equilíbrio de poder entre as elites regionais proprietárias de terras do que o surgimento de novas forças sociais, levando os militares ao centro do poder - onde permaneceram durante sessenta anos (FAUSTO, 1997).

As eleições de 1933 para a Assembleia Constituinte e a Constituição redigida no ano seguinte pretendiam inaugurar um ciclo de democratização, mas o surgimento, em 1935, da Aliança Nacional Libertadora (ANL) e uma tentativa fracassada dos militantes comunistas de tomarem o poder em novembro de 1935 levaram o país ao estado de sítio. Quando as eleições do novo governo, em janeiro de 1938, ameaçaram produzir um resultado inaceitável para Vargas e os militares - a saber, a restauração da antiga democracia liberal dominada pelas oligarquias e grupos cafeeiros -, o processo foi imediatamente abortado por um golpe militar (em novembro de 1937), permanecendo Vargas no poder pelos próximos oito anos (CAMARGO, 1989).
O governo de Getúlio Vargas foi reconhecido pelo desenvolvimento econômico e pela modernização, mas, também - e de forma não menos importante -, pela mudança da relação entre Estado e sociedade; sobretudo pelas relações estabelecidas com a classe trabalhadora urbana. Os sindicatos foram organizados e constituíram as primeiras organizações autônomas da sociedade civil no Brasil. No entanto, suas primeiras mobilizações (durante as primeiras décadas do século $X X$ ) foram duramente reprimidas pelas forças policiais. Conforme a indústria brasileira, após a grande depressão, se expandia - principalmente ao longo da Segunda Guerra Mundial -, grandes setores da classe trabalhadora foram, aos poucos, atraídos para um relacionamento íntimo com o Estado, que pregava uma ideologia de colaboração e harmonia de classe. Algumas das leis do Estado Novo referentes às legislações trabalhistas permanecem em vigor ainda hoje.

No final da Segunda Guerra Mundial, a ditadura Vargas sofreu uma considerável pressão para liberalizar o sistema político do Brasil. No entanto, essa pressão era muito mais internacional do que interna. Vargas, então, prometeu eleições livres, certo de que tinha os meios (através do seu pleno controle dos aparelhos de Estado) e o apoio (especialmente da classe trabalhadora) para vencê-las. Um ponto significativo em todo esse processo foi que, tanto os partidos pró-Vargas quanto os partidos de oposição escolheram representantes militares como candidatos à presidência. Nenhum deles, no entanto, tinha muito apelo popular - com certeza tinham menos do que o próprio Vargas e/ou que Luís Carlos Prestes, então líder do Partido Comunista Brasileiro que 
passara na prisão todo o período do Estado Novo.

Entre maio e outubro de 1945, as principais cidades brasileiras sofreram uma imensa mobilização política das massas, orquestrada em parte pelo PCB e, mais particularmente, pelos chamados queremistas ("queremos Getúlio"). Havia o crescente receio dos setores mais conservadores da população de que as forças populares estivessem sendo perigosamente radicalizadas e, em meio a tal contexto, viu-se a emergência de um novo golpe militar (que, dessa vez, retiraria Getúlio Vargas da presidência) visando garantir as eleições marcadas para dezembro daquele ano que, vencidas pelo general Dutra (ex-ministro da guerra de Getúlio Vargas), representava as forças políticas que haviam sustentado o Estado Novo.

A recém implementada "democracia" brasileira era, portanto, muito restrita (no que diz respeito ao seu alcance) e fundamentalmente antipopular. $O$ preço deste tipo de exercício da democracia foi o permanente controle - por parte do Estado da mão-de-obra organizada, as restrições permanentes à participação política (sem a extensão do voto, por exemplo, à metade analfabeta da população) e a repressão violenta ao comunismo (sobretudo depois que o partido recebera quinhentos mil votos cerca de $10 \%$ do total - tanto nas eleições presidenciais e legislativas de 1945 quanto nas eleições estaduais para governadores e assembleias municipais em 1947). Finalmente, apesar de ter sido eleito um general para a presidência do Brasil, foram garantidos os poderes políticos independentes dos militares; poderes sobre os quais nenhum governo, sem o devido apoio, sobreviveria no poder (BETHELL, 1996).
Estimulada pelo rápido crescimento econômico, essa democracia limitada do pósguerra sobreviveria a algumas crises. Dentre elas, o suicídio de Getúlio Vargas, em agosto de 1954, como consequência da pressão dos militares para que renunciasse e, também, a renúncia de Jânio Quadros, em agosto de 1961 - depois de apenas oito meses no cargo -, cujos numerosos problemas incluíam a sua relação também pouco saudável com os militares. No entanto, no início da década de 1960 e agora com um nível muito maior de participação popular na política, vários fatores se combinaram dentre eles uma forte recessão econômica e o impacto da revolução cubana - para que as forças populares fossem radicalizadas no Brasil. Os trabalhadores e a esquerda política passaram a exigir transformações sociais e econômicas imediatas. As parcelas conservadoras da população dentre elas extensos setores da classe média urbana - estavam prontas para encorajar mais um golpe militar se considerassem este o único caminho para impedir a mudança (considerada radical) imediata que a esquerda política e os trabalhadores buscavam. E foi assim, superestimando o poderio das forças favoráveis às mudanças imediatas e subestimando o poderio da estrutura de poder vigente - tanto militar quando civil -, sua unidade e capacidade de decisão quando ameaçados os seus interesses, que o presidente João Goulart, tentando dar abertura à esquerda para que o país se desenvolvesse, sofre um golpe. O dia 31 de março de 1964 marca, portanto, o fim da experiência com a democracia do Brasil pós Segunda Guerra. Foi pouca, naquele momento, a resistência popular (SANTOS, 1986). 
Assim como em 1945, a liberalização política das décadas de 1970 e 1980 foram iniciadas e controladas do alto. Não foi, em princípio, uma resposta dos militares às vitórias de MDB/PMDB que fizeram oposição nas eleições de 1974 e 1982, ou ao surgimento inesperadamente vigoroso da sociedade civil na forma do novo sindicalismo de 1978 e 1979, ou na formação do Partido dos Trabalhadores (PT), ou mesmo à extraordinária mobilização da população em favor das diretas já (movimento popular que pedia eleições diretas para presidente), em 1984 - embora cada uma delas tenha tido seu papel. Mais do que isso, o regime militar buscou consolidar e fazer progredir sua própria institucionalização. Somente quando perderam o controle do processo de sucessão presidencial, não sendo mais possível contar com a maioria do colégio eleitoral, é que os militares deram o peso de seu apoio a um acordo pretendido pelos dissidentes do PDS (que formariam o Partido da Frente Liberal (PFL)) com os oposicionistas do PMDB. Tancredo Neves, político de oposição liberal-conservadora, se tornaria candidato oficial à presidência e conduziria o processo de redemocratização do Brasil. No entanto, após eleito e na véspera de sua posse como presidente, é alvo de um doença infecciosa que o leva a óbito. A presidência, então, foi assumida por José Sarney (vice-presidente de Tancredo Neves) que, embora civil, fora ex-presidente do ARENA, partido governista durante o regime militar.

Em 1985, a transição do regime militar ao civil (mas ainda não democrático) foi feito pacificamente (do ponto de vista político). Foi uma transição pactuada e sem ruptura. A Nova República, sendo uma forma limitada de democracia, estava comprometida em sua origem. Foi construída sobre a base institucional do regime autoritário que substituiu (MARTINS, 1986). Assim, Sarney presidiu o país em uma transição genuína para a democracia, culminando na eleição presidencial de 1989, baseada no sufrágio universal. Contudo, a eleição de 1989, como nos mostra a história, não foi vencida pelo PMDB (principal partido de oposição ao longo de mais de vinte anos de regime militar e, de longe, o maior e mais amplo partido do Brasil), nem pelo PDT (partido de Leonel Brizola, herdeiro de Getúlio Vargas e João Goulart), nem pelo PT (recém criado partido de oposição cujo líder, Lula, chegou ao segundo turno das eleições), mas o PRN, de Fernando Collor de Mello, político até aquele momento praticamente desconhecido. Seu sucesso, apesar da pouca expressão do partido que fazia parte, se deu graças a impressão positiva que passava para as classes dominantes em outras palavras, era uma alternativa à direita contra outros dois candidatos à esquerda, nas figuras de Lula e Brizola $\underline{11}$.

A eleição de 1994, mais uma vez, não foi vencida nem pelo PMDB, nem pelo PDT, nem PT, mas pelo igualmente inexpressivo PSDB de Fernando Henrique Cardoso, candidato que se elegeria apoiado por partidos de centro-direita, especialmente o PFL. Em 1994, mais do que em 1989, o principal objetivo dos quadros conservadores do Brasil era o de derrubar Lula, que, seis meses antes das eleições, apresentava uma significativa liderança nas pesquisas de opinião. Foi o Plano Real que, efetivamente, garantiu a vitória de Fernando Henrique Cardoso, garantindo o apoio das parcelas mais pobres da população.

\footnotetext{
${ }^{11}$ No primeiro turno, Color conseguiu 30,5\% dos votos válidos, Lula 17,2\% e Brizola 16,5\%. No segundo turno, Collor obteve $53 \%$ contra $47 \%$ de Lula.
} 
À luz da história política, da cultura política e do sistema político brasileiro que tentamos descrever no presente artigo, o crescimento do PT merece menção. Lula aumentou seus votos em 1989 de 17\% (no primeiro turno), para 27\% em 1994 e 32\% em 1998. Em cada eleição, desde 1990, o Partido dos Trabalhadores aumentou - a cada uma delas - duas cadeiras no Senado e na Câmara dos Deputados, assim como o número de estados e municípios. É certo, portanto, que o Partido dos Trabalhadores mudou a agenda política do Brasil - tanto que, em 2002, conquistaria o poder nacional.

\section{CONSIDERAÇÕES FINAIS: DEMOCRACIA, CIDADANIA E JUSTIÇA SOCIAL}

Uma vez que as três administrações brasileiras democraticamente eleitas na década de 1990 dependeram do apoio no Congresso, dos partidos conservadores e dos partidos de centro que, exceto em sentido retórico, não valorizam em seus programas os temas sociais, já que foram restringidas em sua capacidade de concentrar-se na questão social pelas exigências da estabilidade macroeconômica, em especial pela necessidade de reduzir o déficit fiscal, pelo lento crescimento econômico e pela realidade da posição do Brasil na economia internacional, e já que os problemas sociais do Brasil são de trato difícil e não suscetíveis a soluções de curto prazo, não surpreende que o progresso nesta área tenha sido muito lento. Ademais, apesar de todos os obstáculos colocados em seu caminho, até mesmo o fato de que o próprio sistema político não tenha sido reformado, os governos poderiam se debruçar sobre a questão social - no mínimo - de maneira mais eficaz.

A quais conclusões podemos chegar ao retomarmos a história do sistema político social do Brasil até o final dos anos 1990 ? "We must educate our masters ${ }^{12}$ ", foi a famosa frase declarada por Robert Lowe na Câmara dos Comuns, quando da aprovação da Lei da Reforma, em 1867 na GrãBretanha. Quase um século depois, Anísio Teixeira, certamente um dos maiores educadores do Brasil, afirmou: "Só existirá uma democracia no Brasil no dia em que se montar a máquina que prepara as democracias. Essa máquina é a escola pública" (TEIXEIRA, A. in: BETHEL, 2002, p. 39). A organização política também foi - e continua sendo - muito importante. A sociedade civil provou, sobretudo com a queda de Fernando Collor de Mello, uma alta capacidade de mobilização e organização - apesar de ser aparentemente menos combativa politicamente do que num passado recente. A ligação da população com programas partidários, é de se notar, enfraqueceu notavelmente.

Finalmente, se a democracia brasileira (ainda jovem) não conseguir apresentar à população não somente os benefícios econômicos, mas, igualmente, demonstrar o esforço em distribuir equitativamente a riqueza e o poder, será passível de fragilidade e terá sempre que se esforçar para atrair o apoio popular. No entanto, cabe lembrar que, assim como o eleitorado de muitos países da América Latina, o eleitorado brasileiro alocado na classe média e alta pode, em certas circunstâncias, se convencer de apoiar a implementação - mais uma - de soluções autoritárias e populistas para

\footnotetext{
12 "Devemos educar nossos mestres/senhores".
} 
seus problemas. Caberá ao país demonstrar que pode combinar o sucesso da democracia representativa com a ampliação da justiça e igualdade social.

\section{REFERÊNCIAS}

BERQUÓ, E.; ALENCASTRO, L. F. A emergência do voto negro. In: Estudos CEBRAP 33, 1992.

BETHEL, L. Brasil: fardo do passado, promessa do futuro. Rio de Janeiro: Civilização Brasileira, 2002.

. A independência do Brasil. História

da América Latina: $\mathrm{Da}$ independência até 1870, vol. III. São Paulo: Editora da Universidade de São Paulo, 2001.

. A América Latina entre a Segunda Guerra Mundial e a Guerra Fria, 19441948. São Paulo: Paz e Terra, 1996.

. The Decline and Fall of Slavery in Nineteenth-Century Brazil. In: Tran-sactions of the Royal Historical Society. Cambridge University Press: 1991.

. Colonial Brazil. Cambridge, Inglaterra: Cambridge University Press, 1987.

CAMARGO, A. $\mathbf{O}$ golpe silencioso: as origens da República corporativa. Rio de Janeiro: Rio Fundo, 1989.

CARVALHO, J. M. Os bestializados: o Rio de Janeiro e a República que não foi. São Paulo: Companhia das Letras, 1987.

FAUSTO, B. A Revolução de 1930: história e historiografia. São Paulo: Companhia das Letras, 1997.

GRAHAM, R. Patronage and Politics in Nineteenth-Century Brazil. Stanford: Stanford University Press, 1990.

HAHNER, J. Emancipating the Female sex: The Struggle for Women's Rights in Brazil, 1850-1940. Duke University Press, 1991.
HOBSBAWM, E. Era dos Extremos: o breve século XX (1914-1991). São Paulo: Companhia das Letras, 1995.

LAMOUNIER, B.; MUSZYNSKI, J. Brasil. In: DIETER, N. (org.). Enciclopedia electoral latino-americana y del Caribe. São José da Costa Rica: Instituto Interamericano de Derechos Humanos, 1993.

MAINWARING, S. P. Brazilian party underdevelopment. Stanford University Press, 1992.

MARTINS, L. The 'liberalization' of authoritarian rule in Brazil. In: org. Guilhermo O"Donnell; Philippe C. Schmitter; Laurence Whitehead. Tranzitions from Authoritarian Rule: Latin America. Baltimore, Maryland: Johns Hopkins University Press, 1986.

PINHEIRO, P. S. Governo democrático, violência e estado (ou não) de direito In: NOHLEN, D. (org.). Brasil: fardo do passado, promessa do futuro. Rio de Janeiro: Civilização Brasileira, 2002.

SANTOS, W. G. Sessenta e Quatro: Anatomia da Crise. São Paulo: Vértice, 1986.

STEPAN, A. O federalismo descentralizado do Brasil: aproximando o governo dos cidadãos? In: org. Dieter Nohlen. Brasil: fardo do passado, promessa do futuro. Rio de Janeiro: Civilização Brasileira, 2002.

VIOTTI, E. The political emancipation of Brazil. In: org. R. Russell-Wood. From Colony to Nation: Essays on the Indpendence of Brazil. Baltimore, Maryland: Johns Hopkins University Press, 1975.

- Independence: the building of a nation. In: COSTA, E. V. da. The Brazilian Empire: Myths and Histories. Chicago, Illinois: University of Chicago Press, 1985.

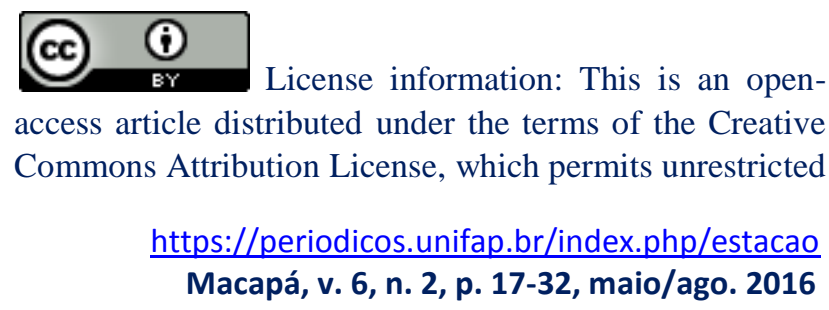


use, distribution, and reproduction in any medium, provided the original work is properly cited.

Artigo recebido em 08 de abril de 2016.

Avaliado em 06 de junho de 2016.

Aceito em 09 de junho de 2016.

Publicado em 03 de novembro de 2016.

\section{Como citar este artigo (ABNT):}

BRANDÃO, Ramon Taniguchi Piretti. Cultura política e processo eleitoral no Brasil. Estação Científica (UNIFAP), Macapá, v. 6, n. 2, p. 17-32, maio/ago. 2016. 